\title{
Algo así como patrocinio en Castilla y León
}

\author{
Antonio Bellido Blanco | Museo de Salamanca, Junta de Castilla y León \\ URL de la contribución <www.iaph.es/revistaph/index.php/revistaph/article/view/4561>
}

Primero. Después de más de tres décadas dándole vueltas a la necesidad de una adecuada Ley de Mecenazgo, sin lograrla, resulta doloroso seguir insistiendo en los mismos puntos. Parece claro que hay instancias políticas que consideran que los impuestos tienen que seguir un cauce determinado y que derivar una parte de ellos hacia temas culturales escuece demasiado. La legislación estatal centra las posibles deducciones fiscales en inversiones en bienes del PHE por parte de sus propietarios, en bienes declarados patrimonio mundial y en determinados museos y reales academias, principalmente. En este marco los museos y la mayoría de bienes patrimoniales quedan en los márgenes del mecenazgo.

Segundo. Si orientamos nuestra mirada hacia Castilla y León, apreciaremos que España sigue siendo un país centralista. El gusto del mecenazgo por las grandes instituciones y el patrimonio cultural de amplio reconocimiento deja a esta comunidad en un espacio de som-

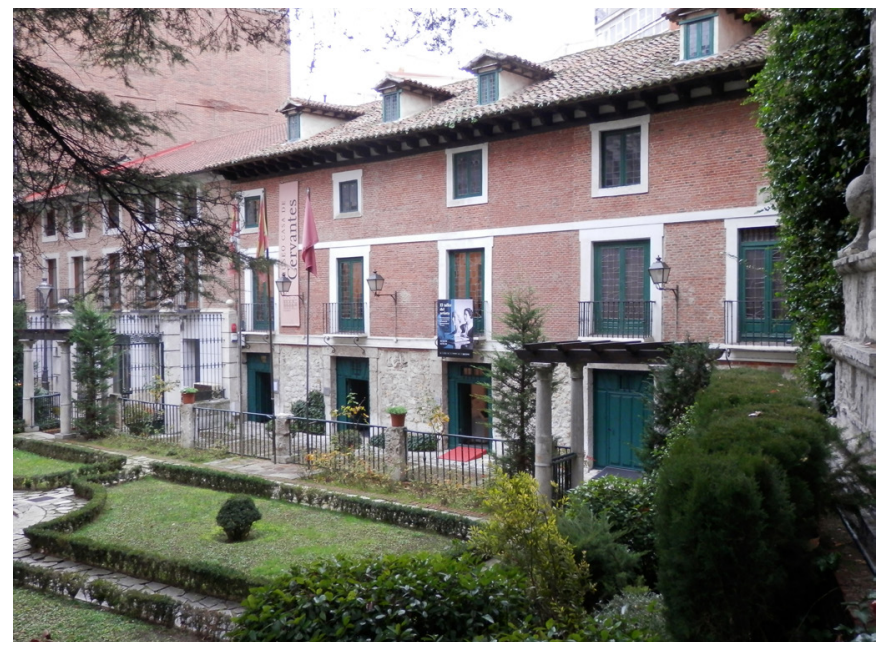

Casa de Cervantes en Valladolid, un ejemplo del mecenazgo del rey Alfonso XIII, Archer Milton Huntington y el Marqués de la Vega Inclán en 1912-1918 | foto Antonio Bellido, autor de todas las imágenes que ilustran este texto bra. Con pocas empresas de sustancial entidad, a veces se puede sentir que "el gran patrocinador regional" es la propia administración autonómica. Ahí están, por ejemplo, las líneas de subvenciones para la mejora en infraestructuras turísticas y patrimoniales que reciben los ayuntamientos de menos de 20.000 habitantes o las dirigidas a personas, comunidades de bienes y personas jurídicas para actuar en bienes inmuebles integrantes del patrimonio cultural.

Pero las inversiones más grandes las reciben entidades de la iglesia católica, ya sean obispados, conventos y monasterios, juntas de cofradías o la Fundación Las Edades del Hombre. De sobra es conocido en estas tierras el recurso a escribir al consejero que toque o incluso al Presidente de la Comunidad, sobre todo si son de la misma provincia que quien solicita. Sin embargo, hasta la Junta de Castilla y León es consciente de sus limitaciones y de la vastedad del patrimonio cultural que debe proteger.

Tercero. Así desde hace un par de legislaturas, como se refleja en el Plan PAHIS 2020, se ha trabajado sobre el principio de "cooperación" para lograr "la conjunción de recursos, tanto de las administraciones públicas como de las entidades privadas y gestoras de los bienes culturales". Una de las Acciones (a79) de este Plan es la "Implementación y desarrollo UnoxUno", que impulsa la colaboración de titulares y gestores de los bienes culturales en aspectos económicos de su conservación y puesta en valor. En octubre de 2017 se hablaba de treinta acuerdos realizados en el marco de esta acción con diputaciones, diócesis, parroquias, monasterios, universidades y fundaciones. Esta colaboración habría permitido hasta esa fecha que a la inversión de unos 14,5 millones de euros por parte de la Junta de Castilla y León se sumasen 7 millones aportados por los titulares de los bienes intervenidos (DIARIO, 2017). 
a debate Patrocinio, mecenazgo, crowdfunding ¿compromiso social o marketing interesado?

| coordina Ana Isabel Velasco Rebollo

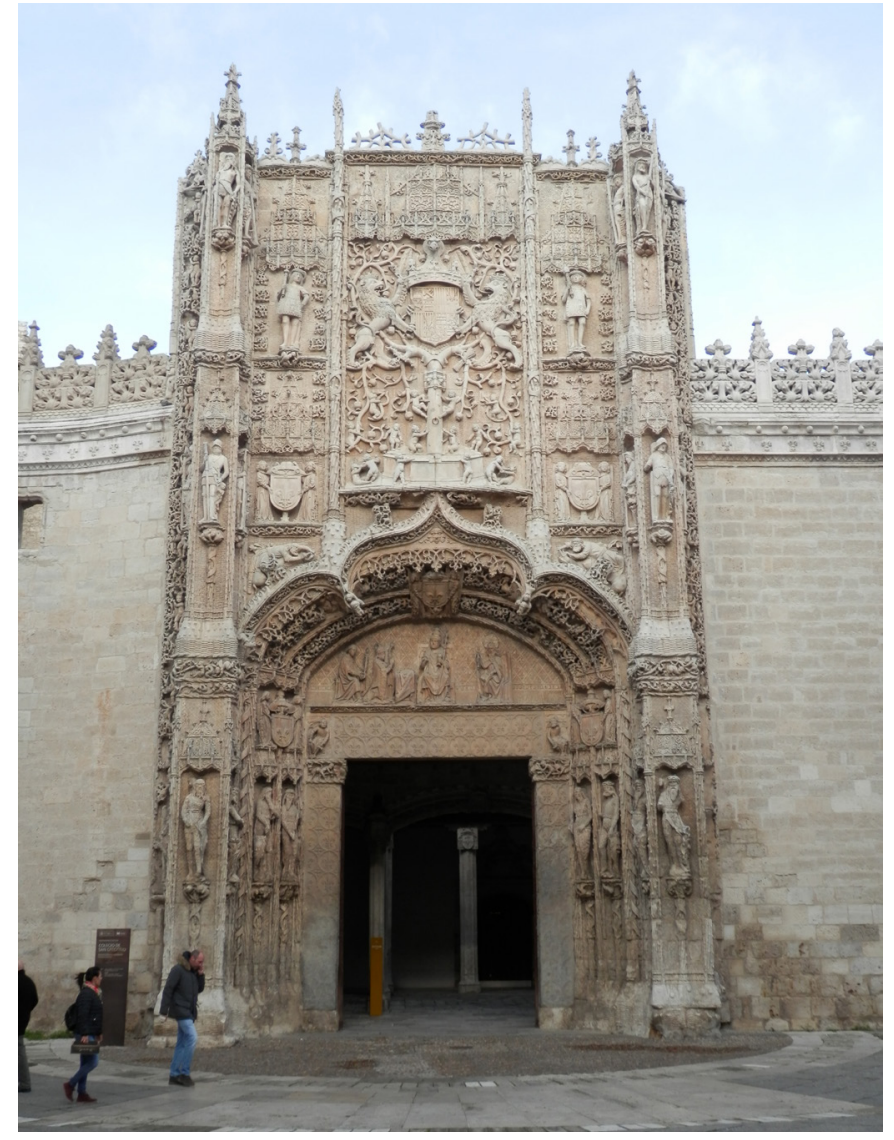

El Museo Nacional de Escultura, exponente de la búsqueda de mecenas en Castilla y León

De hecho el mecenazgo más real sólo vendría de las fundaciones, cuya presencia no resulta especialmente destacada en Castilla y León. Entre los casos concretos cabe aludir a la Fundación Reale en la iglesia de Santa Águeda (Sotillo de la Ribera, Burgos, 2016-2017) o la Fundación Monte Madrid en la Colegiata de San Isidoro (León, 2018-2019). Más importante es el papel de la Fundación Iberdrola, que participa desde 2010 en el Proyecto Románico Atlántico ${ }^{1}$ en colaboración con el Ministerio de Cultura de Portugal y la Junta de Castilla y León que se ha plasmado en 28 edificios religiosos de Porto, Bragança, Vila-Real, Salamanca y Zamora.

Pero buena parte de las ayudas de la Junta de Castilla y León están abastecidas gracias a la financiación euro- pea de los fondos FEDER -dinero público- y se da además una importante presencia de la Fundición Santa María la Real en su gestión. A ello se suman de nuevo las aportaciones europeas a través del Programa de Cooperación Interreg España-Portugal (POCTEP)².

Cuarto. Si centramos nuestra mirada en las instituciones culturales, vemos que archivos y bibliotecas tienen difícil conseguir patrocinio, ya sea para adquirir fondos bibliográficos y documentales o para costear la digitalización de sus colecciones. Aunque la Biblioteca Nacional recibe frecuentemente donaciones de archivos y bibliotecas de escritores e intelectuales, en nuestra Comunidad termina siendo la administración titular la que ha de costear estas iniciativas.

Más fácil debería ser lograr apoyo económico para los museos, aunque estamos suponiendo mucho. Algunos de ellos, como el Museo-Casa Lis, el Museo Etnográfico de Castilla y León, el Museo de Arte Contemporáneo Esteban Vicente, el Museo de la Ciencia de Valladolid o el Museo Patio Herreriano, contemplan el alquiler de sus instalaciones para reuniones, presentaciones o seminarios -e incluso comidas, como en el Museo de Historia de la Automoción, o bodas, como en el Museo de la Energía de Ponferrada- aunque, si bien sirve para conseguir ingresos, esto no es ni de lejos un modo de mecenazgo.

Quinto. Quizás la institución que mejor tenga desarrollada la búsqueda de financiación sea el Museo Nacional de Escultura. Además del alquiler de espacios (regulado por la Orden del Ministerio de la Presidencia de 18 de enero de 2000), contempla la donación de obras de arte, la organización de actividades culturales y la búsqueda de patrocinadores a través de su asociación de amigos. Un ejemplo de lo último es el convenio de colaboración que la asociación firmó en 2016 con el Ministerio de Educación, Cultura y Deporte para buscar y canalizar los posibles patrocinios para la exposición Últimos fuegos góticos.

Y llegan mucho más lejos, abriendo el museo a un mecenazgo total, como se expone en su página $w^{2} b^{3}$ 
(con datos actualizados en el año 2015). Las líneas prioritarias que ofrecen incluyen encuentros y congresos, renovación de la exposición permanente, exposiciones temporales, "la obra invitada", conciertos, conferencias, proyecciones de cine, proyectos de integración social, desarrollo de aplicaciones tecnológicas y publicaciones, además de donaciones de obras. La efectividad de su aplicación es relativamente baja, aunque hasta 2013 había algunos patrocinios significativos por parte de EUROPAC, la Fundación Orange y la Fundación Telefónica (GUILARTE, 2013) y en 2015 se menciona la colaboración de la Fundación La Caixa, AIE Clásicos en Ruta, la bodega Pagos del Rey y la Alianza Francesa (MUSEO, 2015).

Final. En resumen, por estas tierras apenas florece el mecenazgo y, por lo visto en los últimos años, el invierno aún va a durar.

\section{NOTAS}

1. http://www.romanicoatlantico.org

\section{2. http://www.poctep.eu/es/inicio-2014-2020}

3. http://www.culturaydeporte.gob.es/mnescultura/relaciones-externas/colabora/mecenas.html

\section{BIBLIOGRAFÍA}

- CONVENIO de Colaboración entre el Ministerio de Educación, Cultura y Deporte y la Asociación de Amigos del Museo Nacional de Escultura para el Patrocinio de la exposición "Últimos fuegos góticos. Esculturas alemanas del Bode Museum de Berlín [en línea] Madrid, 3 de mayo de 2016 <https://transparencia.gob.es/servicios-buscador/ contenido/conveniosyencomiendas. htm? id=Convenio ECD201602397\&lang=es\&fcAct=2016-11-12T11:14:15.334Z> [Consulta: 12/12/2019]

- DIARIO de Sesiones de las Cortes de Castilla y León, Comisión de Cultura y Turismo (2017) [en línea], n. ${ }^{\circ} 382 / 9,10$ de octubre de 2017 <http://sirdoc.ccyl.es/sirdoc/PDF/PUBLOFI/ DS/COM/9L/DSCOM0900382A.pdf> [Consulta: 03/02/2020]
- GUILARTE CALDERÓN DE LA BARCA, C. (2013) Contra el vicio de no dar, la virtud de pedir. Experiencias de patrocinio en un museo estatal. En CENTENO DEL CANTO, P. (coord.) Actas de las 6as Jornadas de Museología 'Propuestas para financiar museos y colecciones' (Museo Sierra Pambley, León, 21 y 22 de noviembre de 2013) [en línea]. León: Fundación Sierra-Pambley, 2013, pp. 92-100 <https://museosp.files. wordpress.com/2014/07/actas-museo-sierra-pambley-20131. pdf> [Consulta: 12/12/2019]

- El MUSEO Nacional de Escultura sube un 23 por ciento de visitantes en 2015 (2015) [en línea], Nota de prensa, Ministerio de educación, Cultura y Deporte, 5 de enero de $2015<$ http:// www.culturaydeporte.gob.es/dam/jcr:60cc86ba-c049-4b3b8619-41c77e166042/np-visitantes-2015.doc> [Consulta: 12/12/ 2019]

- PLAN PAHIS 2020 del Patrimonio Cultural de Castilla y León (2015) [en línea], Junta de Castilla y León <https:// patrimoniocultural.jcyl.es/web/jcyl/PatrimonioCultural/es/ Plantilla100/1284407871843/_/__> [Consulta: 12/12/2019] 